\title{
Predictors of hearing aid use time in children with mild-severe hearing loss
}

\author{
Elizabeth A. Walkera, Meredith Spratford ${ }^{b}$, Mary Pat Moeller ${ }^{b}$, Jacob Oleson ${ }^{c}$, Hua Ou ${ }^{a, c}$, \\ Patricia Roush $^{d}$, and Shana Jacobs ${ }^{d}$ \\ aDepartment of Communication Sciences and Disorders, University of lowa \\ ${ }^{b}$ Center for Childhood Deafness, Boys Town National Research Hospital \\ 'Department of Biostatistics, University of lowa \\ dDepartment of Otolaryngology, University of North Carolina - Chapel Hill
}

\begin{abstract}
Purpose-This study investigated predictors of hearing aid (HA) use time for children with mild-severe hearing loss. Barriers to consistent HA use and reliability of parent report measures were also examined.

Method-Participants included parents of 272 children with hearing loss. Parents estimated the amount of time the child used HAs daily. Regression analysis examined the relationships among independent variables and HA use time. To determine parental accuracy of HA use time, datalogging from the HA was compared to parental estimates.
\end{abstract}

Results-Longer HA use related to older age, poorer hearing, and higher maternal education. Parental consistency ratings revealed similar findings; younger children and children with milder hearing losses wore HAs less consistently than older children and children with more severe hearing loss. Parents' estimates and datalogging were significantly correlated; however, results suggested parents overestimate the amount of time their children wear their hearing aids.

Conclusions-The findings provide evidence that certain variables were significantly related to the amount of time children wore their HAs. Consistency rating scales provided insight into circumstances that were challenging for families. Use of both parental reports and datalogging may allow clinicians and researchers to obtain a general estimate of HA use time.

\section{Introduction}

As a result of universal newborn hearing screening, infants with hearing loss have earlier access than ever before to intervention. Recent data indicate that more than $95 \%$ of infants born in the United States are screened for hearing loss at birth (Russ, White, Dougherty, \& Forsman, 2010). Early confirmation of hearing loss leads to early fitting of hearing aids on infants (Spivak, Sokol, Auerbach, \& Gershkovich, 2009), and age at fitting of amplification

Copyright 2012 by American Speech-Language-Hearing Association.

Corresponding author: Elizabeth A. Walker, 250 Hawkins Drive, University of Iowa, Iowa City, IA 52252, 319-335-6851, elizabethwalker@uiowa.edu.

This is an author-produced manuscript that has been peer reviewed and accepted for publication in Language, Speech, and Hearing Services in Schools (LSHSS). As the "Papers in Press" version of the manuscript, it has not yet undergone copyediting, proofreading, or other quality controls associated with final published articles. As the publisher and copyright holder, the American SpeechLanguage-Hearing Association (ASHA) disclaims any liability resulting from use of inaccurate or misleading data or information contained herein. Further, the authors have disclosed that permission has been obtained for use of any copyrighted material and that, if applicable, conflicts of interest have been noted in the manuscript. 
is predictive of speech perception, speech production, and spoken language skills (Sininger, Grimes, \& Christensen, 2010). Furthermore, early identification and intervention have a positive impact on the speech and language outcomes of young children with hearing loss (Carney \& Moeller, 1998; Yoshinaga-Itano, Sedey, Coulter, \& Mehl, 1998). In the era of early identification, it is typically assumed that children who achieve consistent, full-time use with their devices will have better outcomes than children who do not wear amplification consistently. However, few studies have explored this variable in young children or the family and child-specific factors that influence consistency of hearing aid use. Primary goals of the current study were to document hearing aid use patterns and identify predictors of the amount of overall hearing aid use time for children with mild to severe hearing loss. Additional goals included identifying barriers to consistent use of amplification and examining the reliability of parent report measures of hearing aid use.

To date, there is little research documenting the consistency of hearing aid use in children. Moeller, Hoover, Peterson, and Stelmachowicz (2009) recently examined longitudinal parental reports of consistency of device use in a group of seven infants with mild to moderate hearing loss between the ages of 10 months and 28.5 months. They administered a structured interview to mothers that evaluated the infants' daily habits with their hearing aids across a variety of environments (e.g., in the car, mealtimes, playing outside, etc.). Results indicated that hearing aid use was inconsistent early in life and became more consistent with age. The authors intentionally chose not to include an estimate of average hearing aid use time because of concerns regarding the reliability of these estimates. They were also unable to include an objective measure such as datalogging at the time of the study because it was not incorporated into the children's hearing aids. Datalogging is an automatic feature built into most current hearing aids (Mueller, 2007), which records performance over time of the hearing aid, including average hours of use time per day. Availability of objective measures, such as datalogging, affords the opportunity to identify variables that predict the amount of time a child is using amplification. Recognizing which variables predict hearing aid use time could help direct audiological counseling practices.

It is also likely that some situations may be more challenging for obtaining consistent device use and these situations may vary by age. Moeller et al. (2009) explored possible challenges by asking parents to identify specific circumstances where it was difficult to keep the device on the child. Parent responses could be grouped into three categories: setting-specific issues, such as inclement weather or noisy environments; temperament/state challenges, such as fatigue, tantrums, or illness; and activity-related issues, such as nursing or playing alone. Even in the narrow age range that they investigated (10.5 to 28.5 months), challenges varied as a function of age. It seems likely that parents would encounter different challenges with device compliance as children enter preschool and early elementary school; however, there is no empirical evidence to support this claim. It may be useful for service providers and parents to recognize which situations pose challenges to consistent hearing aid use across early childhood. This information can be used to counsel parents on realistic expectations as part of the hearing aid adjustment process.

Unfortunately, relying on parental report to document daily hearing aid use has its limitations, as discussed in Moeller et al. (2009). The primary limitation is the questionable accuracy of parents in estimating their children's average daily use time. There are no studies to date that examine the reliability of parents as proxy reporters, although there are several studies that explored the accuracy of adult hearing aid users in reporting their own use time. Humes, Halling, and Coughlin (1996) monitored 20 adults with binaural hearing aids over a 6-month period, using measures from a datalogging feature compared to participant report. They found a strong correlation $(r=0.76)$ between the average number of hearing aid use hours indicated by objective datalogging measures and those reported by the 
research participants. However, on average, participants overestimated the amount of time they wore their hearing aids by about 4 hours per day. These findings suggested that while the absolute value of subjective estimates of overall use was not accurate, the relative difference between users' estimations appeared to be consistent, resulting in valid estimates of overall use time.

Taubman, Palmer, Durrant, and Pratt (1999) used a different approach to investigate subjective estimates of hearing aid use time in adults. Participants included 24 adult HA users ranging in age from 50 to 90 years. Half of the participants (experimental group) were informed that their self-reported use time would be monitored using datalogging, and half were not (control group). There was a significant difference between the control group and the experimental group in the magnitude of difference between datalogging and selfreported use time, with the control group demonstrating a larger absolute difference between the two measures. Based on these findings, Taubman et al. concluded that clinicians and researchers should not rely on self-report estimates of average hearing aid use time because they may be inaccurate. These conclusions may be overstated, however. Taubman et al. did not report on the correlation between self-report measures and datalogging. Working from the raw data in Table 1 (Taubman et al., 1999, p. 303), it can be determined that the relationship between datalogging and self-report estimates for the whole group was highly correlated $(r=.72)$. These results were consistent with the findings of Humes et al. (1994), in that the absolute value of estimates was inaccurate by several hours, but the correlation between objective and subjective measures was high. In other words, adults tended to overestimate their average overall use time, but that overestimation occurred to the same degree across all hearing aid users.

It seems reasonable to predict that parents, serving as proxy reporters of children's average use time, may be less accurate than adult hearing aid users at estimating the amount of time their child is wearing his or her hearing aids. There often will be occasions when parents are not present (e.g., daycare or at a friend or relative's house) and possibly uninformed about the child's hearing aid use. It is also difficult to estimate average daily use time in children because of fluctuating schedules. Parents will encounter situations where it is appropriate not to wear hearing aids, such as nap time or bath time. Some of these situations would occur with younger children, suggesting that parents' accuracy in reporting hearing aid use time will increase as children get older. The present study investigates the accuracy of parents' estimates of hearing aid use time, while also exploring variables that may predict which parents are more accurate reporters.

In general, there are many gaps in the literature concerning children with mild to severe hearing loss (Moeller, Tomblin, Yoshinaga-Itano, Connor, \& Jerger, 2007), in spite of high prevalence rates. Recent estimates for childhood hearing loss indicate that there is an average prevalence of $.9 \%$ (range $.4 \%$ to $1.7 \%$ ) for mild hearing loss or worse (pure-tone average of 500, 1000, and $2000 \mathrm{~Hz}$ greater than $25 \mathrm{~dB} \mathrm{HL}$ ) (Mehra, Eavey, \& Keamy, 2009). Given these data and the lack of information about the unique strengths, needs and challenges for these children, the National Institute on Deafness and Other Communication Disorders (NIDCD) funded a collaborative research team to investigate the speech, language, academic, psychosocial and family outcomes of children who are hard of hearing. The Outcomes of Children with Hearing Loss (OCHL) study is a five-year multi-center study conducted by investigators representing three primary sites and multiple disciplines. The aims of the OCHL study are to examine background characteristics of the child and family and their interventions and explore how variations in these factors relate to functional outcomes. The current article reports on results for two studies and addresses the following research questions:

Study 1 
1) Which child- and family-specific variables predict hearing aid use time in children who are hard of hearing?

2) What challenges do parents encounter with hearing aid compliance across ages and situations?

Study 2

3) Are parents accurate at estimating average daily hearing aid use time?

4) Which child- and family-specific variables predict how accurate parents are at estimating average daily hearing aid use time?

\section{Study 1 \\ Method}

Purpose-Study 1 sought to determine which child- and family-specific variables predicted the amount of time children wore their hearing aids, on average, during the week and on weekends. Study 1 also examined the variation of pediatric hearing aid use across listening environments, as well as the challenges different situations posed for consistent hearing aid use.

Participants-Participants were parents of 272 children with hearing loss. The children included 127 females and 145 males who were between the ages of 5 months and 7 years, 3 months ( $M=40.51$ months; $S D=21.28$ months). All of the families were participants in the longitudinal study on outcomes of children with mild to severe hearing loss (OCHL). To qualify for participation, children presented with a permanent bilateral hearing loss (sensorineural, mixed, and permanent conductive) with a better-ear three- or four-frequency pure-tone average (PTA) no better than $25 \mathrm{~dB}$ HL and no poorer than $75 \mathrm{~dB}$ HL. Children with significant cognitive, visual or motor impairments were excluded from participation. For all participants, at least one primary caregiver spoke English in the home. Children who used manually-coded English or American Sign Language as their primary mode of communication were excluded from the study.

Two-hundred eleven children were identified with HL at birth based on a failed newborn hearing screen (NHS), according to parent report. Of those 211 participants, the mean age at confirmation of hearing loss was 7.36 months $(S D=13.97)$ and the mean age at fitting of amplification was 10.99 months $(S D=11.78)$. Sixty children were identified with hearing loss after birth. Of those 60 children, 35 passed the NHS, 14 failed the NHS but there was no follow-up testing during the first year of life, 4 were not screened at birth, 1 had an inconclusive NHS, 1 had bilateral atresia and 5 had an unknown status regarding NHS (due to international adoption or parental uncertainty). For one additional child, parents did not report if the child was identified with HL at birth or later. For those participants identified with HL after birth, the mean age at confirmation of hearing loss was 27.28 months ( $S D=$ $17.1)$ and the mean age at fitting of amplification was 30.4 months $(S D=17.74)$. The mean better-ear PTA for the whole group was $49.58 \mathrm{~dB}$ HL ( $S D=13.72)$. Two-hundred sixty-five children were fitted with wide dynamic range compression hearing aids and 7 had bone conduction hearing aids. No participants had cochlear implants (CIs) at the start of the study, although six received CIs following enrollment due to progression of the hearing loss. At the time of data collection for Study 1, no children used CIs.

Data collection-Children and their families participated in an initial baseline visit, followed by visits twice a year for children under age 2 and once a year for children older than 2 years for up to four years. Visits consisted of an audiologic assessment including evaluation of hearing aid function and administration of age-appropriate speech, language, 
and cognitive measures (see Appendix A for a summary of the OCHL test battery). Parents completed questionnaires and participated in a face-to-face interview regarding hearing aid compliance (described below) at each visit. To avoid repeated measures, we included data from only one visit per subject. For all analyses in Study 1, these data were from the initial baseline visit.

Audiologic assessment-A certified audiologist with pediatric experience completed all hearing assessments. A test assistant participated in assessments as needed. The audiologist attempted to obtain air-conduction and bone-conduction thresholds at 500,1000, 2000, and $4000 \mathrm{~Hz}$ at a minimum, using visual reinforcement audiometry, conditioned play audiometry, or conventional audiometry depending on the age of the child. All attempts were made to obtain ear-specific thresholds utilizing insert earphones, circumaural headphones, or the child's own earmolds paired with insert earphones. Audiologists obtained soundfield thresholds if the child would not tolerate the testing with earphones or headphones. If a full audiogram could not be completed, the audiologist obtained a copy of the child's most recent unaided audiogram. The better-ear PTA was calculated for subsequent analyses.

Hearing aid verification measures-Hearing aid measurements included measures of total harmonic distortion, frequency range, and output sound pressure level at $90 \mathrm{~dB}$ SPL obtained in a 2 cc coupler following ANSI S3.22 (2003). In addition, the audiologist conducted probe microphone measures to quantify the real-ear-to-coupler-difference (Bagatto et al., 2005). Hearing-aid verification was then completed in a $2 \mathrm{cc}$ coupler. Audioscan Verifit software calculated aided and unaided SII, using the standard male speech signal (carrot passage) presented at 65dB SPL and $50 \mathrm{~dB}$ SPL, following ANSI S3.5 (1997). A swept pure tone at $90 \mathrm{~dB}$ SPL measured maximum output. The obtained fitting data were compared to prescriptive targets for DSL 5.0. These analyses are beyond the scope of the present analysis and are reported separately (McCreery, Bentler, \& Roush, in revision). Based on the results of the hearing aid verification measures, parents received a report informing them if the settings of the hearing aids needed adjustment or if the hearing aids were in need of repair. Parents were also given the option of receiving a print-out of the hearing aids' responses to share with their child's audiologist. Of the 272 children in Study 1 , eight families were notified regarding problems with hearing aid function. This low number is likely to due to the fact that families were encouraged (via phone calls and postcards) to perform listening checks prior to scheduled research visits, and contact examiners if the hearing aids were not functioning appropriately. In these situations, visits were rescheduled for after the malfunctioning hearing aid had been repaired.

Hearing aid provider survey-Each child's audiology service provider was encouraged to complete a survey that was designed to obtain information about the HA fitting audiologist's experience and clinical practices. Surveys included specific questions regarding the hearing aid fitting and verification methods used as well as the audiologist's comfort level with pediatric assessment and amplification procedures. For the 272 children in Study 1, we received 200 responses to the audiology service provider survey. Sixty-five of these were unique audiologists; in other words, many of the same audiologists responded to the surveys because they served multiple children in the study. Based on the audiology survey responses, the vast majority of children (over 90\%) were fit with age-appropriate fitting and verification methods. Data on fitting and verification techniques, as well as quality of the hearing aid fit for the participants, may be found in McCreery et al. (in revision). 
Hearing aid use questionnaire-As part of the visit, an examiner conducted an interview with the caregiver that pertained to pediatric hearing aid use. Parents estimated the average amount of time the child used hearing aids per day during the week and on the weekends. Parents also indicated consistency of use across contexts using a 5-point Likert scale adapted from a previous study on hearing aid use in infants (Moeller et al., 2009). Examiners asked the caregiver to rate how often the child wore his/her hearing aids in eight different listening environments: in the car, at school, at daycare, during meal times, while playing alone, during book sharing, on the playground, and in public (e.g., at the zoo, in a store). The scale included the following ratings: $0=$ never, $1=$ rare, $2=$ sometimes, $3=$ often, $4=$ always, and not applicable. The questionnaire also included an open-ended question, which asked the caregiver to identify any situations in which it was challenging to get the child to wear hearing aids. The hearing aid use questionnaire can be found in Appendix B.

\section{Statistical analyses}

To investigate the relationships among the independent predictor variables and the dependent response variables, we utilized linear regression models. The independent variables were chronological age, gender, site (University of Iowa, Boys Town National Research Hospital, and University of North Carolina-Chapel Hill), maternal education level, and better-ear PTA. The dependent variables were parent-report estimates of average hearing aid use time during weekdays and weekends. Due to the large number of maternal education categories collected, arbitrary ordinal levels were introduced in the data analysis. Details about the number of participants comprising each of the ordinal levels for maternal education are presented in Table 1. Dummy variables represented categorical variables in the statistical model. The selection of the best set of predictor variables was based on Pearson's correlation and Akaike's information criterion (Akaike, 1974). Residual analyses were examined and linear regression assumptions were appropriately satisfied. A quadratic effect for age was statistically significant and included in the final model to account for the curvilinear relationship between chronological age and hours of use.

Data regarding hearing aid use consistency across contexts and challenges to hearing aid use were explored descriptively. In this section, participants were divided into three age groups: infants ( $0-2$ years), preschool ( $3-4$ years), and school-age (5-6 years). The rationale for this division was motivated in large part by Moeller et al. (2009), who demonstrated that issues with infants/toddlers are somewhat unique. Thus, we felt that it was important to contrast children under two with older children. There are also reasons to suspect that school-age issues may differ from preschool, as children become more independent with their devices (in contrast to preschoolers who may be dependent on a child care worker's device knowledge). In further analyses, participants were divided into two groups based on betterear PTA: 1) PTA less than $50 \mathrm{~dB}$ HL, and 2) PTA greater than $50 \mathrm{~dB}$ HL. We separated the participants into two PTA groups as a further attempt at reducing the data to gain insight into factors that influenced use. The selection of $50 \mathrm{~dB}$ HL was the mean PTA of the group, and indicated an effort to compare children with mild-moderate degrees of HL to children with moderately-severe degrees of HL.

\section{Results}

Descriptive statistics and multivariate regression-Table 2 presents descriptive statistics summarizing both the independent and dependent variables. On average, parents reported that their children wore their hearing aids around 10.5 hours per day during the week and around 10 hours per day during the weekends. A paired-sample t-test indicated that hearing aid use time was statistically significantly higher during the week than on the weekend, $t(269)=4.45, p<.0001$. 
The regression analysis indicated that chronological age $(p<0.0001)$, better-ear PTA $(p=$ $0.0002)$, maternal education level $(p=0.0066)$, and site $(p=0.0181)$ had statistically significant effects on hearing aid use time during weekdays. Longer hearing aid use time was associated with older age, poorer hearing, and higher maternal education level. Table 3 presents the individual parameter estimates $(\beta)$ and related statistics for each predictor variable. For example, the parameter estimates indicated that for every $10 \mathrm{~dB}$ increase in better-ear PTA, the predicted average hearing aid use time increased by 0.50 hours with all other predictor variables held constant; for every 10 months increase in age, the predicted average hearing aid use time increased by 0.71 hours with all other predictor variables held constant. Note that the two chronological age variables must be considered simultaneously when interpreting the data. The quadratic effect of chronological age $(\mathrm{p}<.0001)$ had a small negative coefficient $(-0.002)$ which indicates that although longer hearing aid use time was associated with older age, the increase in hours of use was smaller at older ages than it was for younger ages. For example, the slope at 10 months of age was $0.2002-0.0015 * 10=0.18$ while the estimated slope at 70 months of age was only half that amount at 0.09 .

The results suggested that the children recruited from the Iowa site $(M=9.83, S D=3.5)$ had significantly less hearing aid use time than those from North Carolina $(p=.04)$. The mean difference of hearing aid use time was approximately 1 hour. There were no significant differences between the North Carolina site $(M=11.14, S D=3.04)$ and Boys Town $(M=$ $10.35, S D=3.12$ ) or between Boys Town and Iowa. In addition, the results indicated that mothers who had obtained a college degree had children with the most hearing aid use time compared to other educational backgrounds. Table 4 displays the mean and standard error of daily hearing aid use time during weekdays for each level of maternal education. The largest mean difference ( 1.9 hours) was observed between children with mothers who had obtained a college degree and those with mothers who had obtained a high school degree or less. The remaining mean differences were less than one hour. There was no significant difference for hearing aid use between female and male children.

To assess whether maternal education level confounded either age or degree of hearing loss, we analyzed a regression model removing maternal education. Confounding is typically considered to be present if the parameter estimates change by more than $10 \%$. The parameter estimates for age and degree of hearing loss each changed by less than $5 \%$ when maternal education was removed from the model, thus indicating that there was no confounding relationship between maternal education and chronological age or degree of hearing loss.

The regression analysis for hearing aid use time during the weekend was similar to that for hearing aid use time during weekdays, with the exception of a lack of significant differences in hearing aid use time between sites. Maternal education level $(p=0.0127)$, better-ear PTA $(p<.0001)$, and chronological age $(p<0.0001)$ had significant effects on hearing aid use time on weekends. There was no significant difference between female and male participants.

Consistency of Use: Unsupervised Versus Supervised Contexts-For data reduction purposes, ratings were combined into categories of always, often/sometimes, and rarely/never. A report of "always" was considered to be full-time use in that context.

Unsupervised context: Car: As seen in Figure 1, only 35\% (37/105) of parents of infants ( $0-2$ yr) responded that their child always used amplification in the car, compared to $78 \%$ (74/95) of parents of preschool (3-4 yr) and 78\% (56/72) of school-age (5-7 yr) children. Table 5 displays use consistency in the car for the infant group in 6-month intervals. Consistent use in the car was the most limited at 12 months of age, with 54\% (15/28) of 
parents indicating that hearing aids were rarely/never worn in the car and only $14 \%(4 / 28)$ reporting that their child always wore their hearing aids in that setting. However, there were improvements after 12 months of age, with 63\% (22/35) of parents of 24-month-olds reporting that devices were always worn in the car.

Supervised by caregiver: Public: As shown in Figure 1, most parents of preschool and school-age children reported that their child always used amplification in public settings ( $81 \%$; 76/94, and 76\%; 55/72, respectively); infants showed less consistency (67\% "always" responses; 70/105). Only 50\% (14/28) of parents of 12-month-old children reported consistent use in public, but consistency ratings improved to $83 \%$ (29/35) for 24-month-olds (see Table 5).

Supervised-by-other context: Daycare: There were similar patterns in the consistency of device use in daycare settings (Figure 1). Infants (58\% "always" responses; 29/50) were less consistent than preschoolers $(38 / 48=79 \%)$ and school-age children $(22 / 29=76 \%)$. Within the infant group (Table 5), only 50\% (4/8) of 6-month-olds and 40\% (4/10) of 12-montholds consistently wore their hearing devices at daycare, but consistency improved at later ages [58\% of 18-month-olds (7/12) and 70\% of 24-month-olds (14/20)].

Context by PTA: Public: Figure 2 shows the differences in consistent device use between children with a better-ear PTA of less than $50 \mathrm{~dB}$ HL and the children with a better-ear PTA of greater than or equal to $50 \mathrm{~dB} \mathrm{HL}$. There was on average more consistent hearing device use in public for children who had a better-ear PTA of greater than or equal to $50 \mathrm{~dB} \mathrm{HL}$. The largest difference in consistent hearing aid use between the two groups was present at 5 years of age (better-ear PTA less than $50 \mathrm{~dB}$ HL: 64\%; 14/22; better-ear PTA greater than or equal to $50 \mathrm{~dB}$ HL: $89 \%$; 16/18).

Context by PTA: School: Consistent use at school varied as a function of better-ear PTA at selected ages. As seen in Figure 2, there was a large difference between 3-year-olds with milder losses (less than $50 \mathrm{~dB} \mathrm{HL}$ ) and those with greater than or equal to $50 \mathrm{~dB} \mathrm{HL}$ (58\%; $7 / 12$, and 94\%; 17/18, respectively). Compared to the 3-year-olds, 4- and 5-year-olds showed less of a difference between PTA groups and were reported to use amplification more consistently at school.

Open-ended responses: Specific challenges to device use-Parents were asked during the interview to describe situations or environments that presented challenges to consistent hearing aid use. Responses were classified into four categories: 1) child state (e.g., mood, illness, fatigue, temperament), 2) breaks in routine (e.g., different care provider, at home on weekends, after bath time), 3) loud events (e.g., movie theater, church), and 4) equipment issues (e.g., feedback from hearing aid, discomfort from ear mold).

Parents of the infant group (0-2 yr) reported challenges to consistent hearing aid use more often than parents of preschool and school-age children, especially in situations related to child state. Figure 3 illustrates that 39\% (41/105) of parents of the infant group, 28\% (27/95) of parents of preschoolers, and $11 \%(8 / 72)$ of parents of school-age children reported that child state was an obstacle to consistent amplification use. Other, less prevalent challenges to hearing aid use across all of the age groups consisted of breaks in routine, loud events, and equipment issues. Within the infant group, child state was more often reported as a challenge for children ages 12- and 18-months $(14 / 28=50 \%$ and $14 / 26=54 \%$, respectively), compared to 6 -month-olds $(3 / 16=19 \%)$ and 24 -month-olds $(10 / 35=29 \%)$. 


\section{Study 2}

Method

Purpose-Study 2 sought to examine the accuracy of parental estimates of average hearing aid use time for children during the week. The accuracy was determined by comparing the parent-report data from the hearing aid use questionnaire to objective datalogging measures acquired from the children's hearing aids. A secondary goal was to investigate variables that may predict parents' accuracy when estimating hearing aid use time in children.

Participants and procedure-A subset of parents and children from Study 1 participated $(\mathrm{n}=133)$. Audiologists began collecting datalogging information after data collection had commenced for some participants in the OCHL study. Once the OCHL audiologists began collecting datalogging, it was collected at each annual visit. However, for the present analysis, only the first datalogging measure was included. For 25 participants, datalogging was collected at the initial baseline visit, at the second visit for 58 children, at the third visit for 45 children, and at the fourth visit for 5 children. The hearing aid use questionnaire was administered to parents at the same visit. Families were unaware that the audiologist was utilizing the datalogging feature during the course of the study. Because data for Study 2 were collected after the initial visit for most participants, the average age of the children was older than in Study $1(M=50.57, S D=25.42)$. All 133 children had wide dynamic range compression hearing aids. Two participants received CIs prior to when the audiologist obtained datalogging information, but continued to wear a hearing aid on the contralateral ear. In both cases, parent estimates of average use time only referred to the hearing aid and not the CI.

Hearing aid datalogging-Audiologists collected values for average use time per day by connecting the hearing aids to a HiPro box and using the appropriate hearing aid software. If the values were different between ears, the larger value was included in data analyses.

\section{Statistical analyses}

To investigate the relationship between the subjective and objective estimates of daily use time, we conducted a Pearson's correlation. In addition, linear regression models were used to investigate the relationships among the independent predictor variables (gender, site, maternal education level, and better-ear PTA) and the dependent response variables (the time difference between parents' reports of hearing aid use time and datalogging). As in Study 1, arbitrary levels were introduced to the data analysis due to the large number of levels within the categorical variable of maternal education. The selection of the best set of predictor variables was based on Pearson's correlation and Akaike's information criterion (Akaike, 1974).

\section{Results}

There was a statistically significant correlation $(r=0.76, p<.0001)$ between parent report and datalogging for hearing aid use time during the week. Furthermore, hearing aid use time reported by parents was significantly related to the time obtained from datalogging $(F 1$, $131]=177.31, p<.0001)$. Parent report of hearing aid use time explained a statistically significant proportion of the variance in datalogging $\left(R^{2}=0.58\right)$. Every one hour increase in parent report of hearing aid use time typically resulted in a 0.95 hour increase of hearing aid use time from datalogging, indicating that parents typically overestimated the amount of time their children were wearing their hearing aids. For parents that report daily hearing aid use was 5 hours, the model average datalogging value was 2.69 hours with the $95 \%$ confidence interval between 1.74 and 3.60 hours. As the parent report of daily hearing aid 
use increased, the bias away from being equal to the datalogging also increased. For parents that reported 10 hours of use, the model average datalogging value was 7.40 with $95 \%$ confidence interval between 6.95 and 7.85. At 15 hours, the model average datalogging value was 12.12 with $95 \%$ confidence interval 11.40 to 12.85 hours. Figure 4 displays the relationship between hearing aid use time from parent report and datalogging.

Data indicated that $84 \%(112 / 133)$ of parents overestimated hearing aid use time, while $16 \%$ (21/133) either underestimated or were accurate in their estimations. On average, parents reported that children wore their hearing aids for 10.84 hours per day $(S D=3.09)$ and datalogging values indicated that hearing aids were worn for 8.3 hours $(S D=3.87)$. This resulted in an average overestimation of 2.6 hours $(S D=2.52)$, but these differences ranged from an underestimation of 2 hours to an overestimation of 10 hours.

We also conducted linear regression models to investigate if child- or family-specific variables could predict the amount of time difference between parents' reports of hearing aid use time and hearing aid datalogging (dependent variable). Independent predictor variables included chronological age, gender, site, maternal education level, and better ear PTA. Table 6 provides a summary of descriptive statistics of independent and dependent variables. Only chronological age was found to have a significant negative effect on the time difference between parents' reports and datalogging $(p=.0008)$. The parameter estimate indicated that for a one-year increase in chronological age, there was an estimated 0.03 hour smaller difference between parent report of hearing aid use and datalogging. In other words, the older the child was, the smaller the expected difference would be between parents' subjective estimates of hearing aid use and objective datalogging measures. Table 7 displays the estimate for each parameter along with related statistics and p-values

\section{Discussion}

In Study 1, we examined hearing aid use time and the factors that predict average hearing aid use time in children who are hard of hearing. A linear regression analysis indicated that three factors - maternal education level, chronological age, and better-ear PTA - influenced hearing aid use time during the week and on the weekends. A fourth factor, testing site, played a role in the amount of time children used their hearing aids during the week, but not on the weekends. On average, children at the North Carolina site wore their hearing aids for one hour longer than children at the Iowa site. It is unclear why there is a difference between the two sites; further examination of the data reveals no significant differences between the Iowa and North Carolina participants in terms of chronological age, better-ear PTA, age at fitting of hearing aids, maternal education level, or number of hours of services (for speechlanguage pathologists, teachers of the deaf/hard of hearing, or early interventionists).

Results showed that maternal education level influences the amount of time children wear their hearing aids. In fact, there was almost a 2-hour difference in reported hearing aid use time between mothers with a college education and mothers with a high school education or less. It does not appear that this difference is the result of overestimation of hearing aid use by mothers with more education or, conversely, underestimation by mothers with less education. The regression analysis in Study 2 indicated that maternal education level did not play a significant role in the difference between datalogging and parental report estimates. The present findings are consistent with a recent study by (Holte et al., in press) looking at the same cohort of OCHL participants, in which maternal education level was the only predictor variable that was significantly related to age at first diagnostic audiology evaluation, confirmation of hearing loss, and fitting of hearing aids (better-ear PTA, research team site, and gender were not significantly related to any of the dependent variables). Together, the findings from these studies highlight the need for continued counseling 
regarding the benefits of consistent hearing aid use in children who are hard of hearing, especially those with milder degrees of hearing loss and for families with lower levels of education. In addition, further study is needed to determine how counseling can be presented most effectively. Moeller et al. (2009) advocated for use of experiential learning methods; simulations of aided and unaided hearing loss and illustrations of developmental outcomes may be more informative than written resources. They stressed the importance of establishing clearer links for parents between consistency of device use and development of speech and language skills. Elfenbein (1994) recommended that audiologists provide a combination of verbal and written material about the consequences of non-use of amplification. At this point, no researchers have investigated the efficacy of counseling parents with regards to this topic.

The findings from the regression analysis demonstrated that older children tend to wear their hearing aids more frequently than younger children. The use of a rating scale for different listening environments highlighted the contexts that were problematic for maintaining consistent hearing aid use, particularly for parents of young children, supporting the findings of Moeller et al. (2009). Not surprisingly, many parents reported that hearing aid use was rare in unsupervised contexts during the toddler years (12 months to 24 months). However, close examination of the data with infants demonstrates that the number of parents reporting challenges due to child state issues increased from 6 months to 18 months of age, but dropped again by 24 months. In addition, by the preschool years, a very high percentage of parents (78\%) indicated that their 3-and 4-year-olds always wore their hearing aids in the car.

These results are important to convey to parents who are frustrated with trying to keep hearing aids on their young children. It may be valuable for parents to recognize that the challenges to maintaining consistent device use are not unique to their child and will fluctuate with age, child-state issues, and different listening environments, but these difficulties are temporary in most cases. However, it is also critical for audiologists to be sensitive to the unique challenges associated with young children, and offer support related to specific issues that are complicating hearing aid use (Moeller, 2010). If parents realize that the challenges they are encountering are typical among caregivers and are not permanent, and if they can discuss alternative strategies and solutions that are tailored to the specific needs of each family, this information may provide the encouragement families need to persevere with trying to achieve full-time hearing aid use.

It may also benefit families to receive specific training related to daily care and maintenance of hearing aids. Elfenbein (1994) reported on a group of 15 families who were participating in an educational program for parents of preschoolers with hearing loss. Over $90 \%$ of the parents reported that they had received counseling about HA monitoring and troubleshooting, but only about half reported performing daily listening checks. Furthermore, two-thirds of the parents did not own moisture reduction kits and one-third did not own basic equipment for monitoring HAs. The present study does not explore parental practices regarding equipment monitoring, but those data are currently being collected as part of the OCHL project. Future reports may address parents' knowledge on daily care and HA maintenance. This will hopefully provide us with more evidence on how to effectively provide parents with specific information about troubleshooting. Perhaps if parents recognize the importance of good audibility for children's speech and language development, they will have a more vested interest in maintaining hearing aid function and achieving consistent device use.

Severity of hearing loss also influences the amount of time children wear their devices, with parents of children with more severe losses reporting more daily hours of hearing aid use 
time than children with milder losses. However, parents' responses on the rating scale indicated that there is a complex relationship between better-ear PTA, the age of the child, and the listening context. For example, at age 3 the largest difference between the two groups (mild-moderate, moderate-severe) occurred at school. Almost all parents of children with moderate-to-severe hearing losses reported that their children wore their hearing aids all the time at preschool. In contrast, a little more than half of the parents of children with mild-to-moderate hearing losses reported that their children wore amplification all the time at preschool. This may reflect a need for further education directed towards preschool teachers regarding the risks of minimal and mild hearing loss (Daud, Noor, Rahman, Sidek, \& Mohamed, 2010; Hicks \& Tharpe, 2002; McFadden \& Pittman, 2008).

By age 5, there does not appear to be much difference in hearing aid use time at school between children with milder versus more severe hearing losses, but there is a large difference at that age in public situations, such as at the grocery store, the zoo, etc. According to parents, 5-year-olds with more severe hearing loss wore their hearing aids more in public situations compared to children with milder losses. It is possible that children with milder losses wear their hearing aids less often in public situations because they can follow some conversation without their hearing aids. In this situation, parents may be more amenable to letting their child not wear amplification. Previous studies have shown that school-age children with hearing impairment experience more difficulties with social isolation compared to peers with normal hearing (Davis, Elfenbein, Schum, \& Bentler, 1986) and are more likely to be rejected by their peers (Cappelli, Daniels, Durieux-Smith, McGrath, \& Neuss, 1995). It is unclear from this literature if these difficulties with socialization result in reduced hearing aid use in public, particularly for children with mild hearing loss who can function somewhat adequately without their hearing aids. Future studies should track consistency of use across listening situations, to determine if this pattern exists as children enter elementary school and social pressure to "fit in" increases. These studies should include consistency ratings across different settings, because this provides different information than parents' reports of overall use time. Both pieces of information are useful to service providers when guiding families through the hearing aid process.

In Study 2, we explored the accuracy of parents' estimates of the average number of hours their child wore hearing aids during the week. Results indicated that parents are fairly accurate reporters of average hearing aid use when accuracy is examined from a relative viewpoint and not absolute terms. Parents usually overestimated the amount of time children wore hearing aids by about 2.5 hours; however, the significant correlation $(r=.76)$ between parent report and objective datalogging measures indicates that most parents were overestimating by about the same degree. It is interesting to note how consistent the correlation in the current study is compared to other studies that have looked at this issue with adults reporting on their own hearing aid use time. Humes et al. (1994) found the same correlation $(r=.76)$ with 20 adults. The adults in that study overestimated the amount of time they wore their hearing aids by an average of 4 hours. Taubman et al. (1999) looked at the reliability of 24 adults in reporting hearing aid use time with a correlation of .72, also consistent with the present findings.

Together, the results from Study 2 suggest that service providers should recognize that the majority of parents may overestimate hearing aid use by a few hours. This appears to be especially true for parents of younger children, as chronological age was the only variable that predicted how accurate parents were in their estimates of use time. It seems reasonable to expect that it would be harder for parents to approximate the number of hours an 18month-old would be wearing hearing aids compared to a 5-year-old. There are many more situations in which hearing aids would be removed (by the parent or the child) in the case of younger children, such as naps, riding in the car, or during temper tantrums, making it 
difficult to provide an accurate estimate of average wearing time. Therefore, use of objective measures like datalogging is preferred with parents of younger children to monitor use of amplification.

The findings from Study 2 also have implications for future studies, as we consider using datalogging or parent report estimates as independent variables in multiple regression analyses of speech and language outcomes. It is assumed that children who use their amplification on a consistent basis will have better speech and language outcomes than children who are not full-time users, but daily use time has not been fully investigated as a predictor variable in outcomes of children who are hard of hearing. Given the results of the present study, it is likely that consistency of hearing aid use contributes to outcomes by interacting with other variables such as degree of hearing loss, quality of the hearing aid fitting, and maternal education level. Our future studies will employ multiple regression analysis to explore which of these variables are predictive of outcomes in the hard-ofhearing population, as well as the ways in which these variables may interact to influence outcomes.

\section{Limitations and Future Directions}

There are several important limitations that should be considered when interpreting the results of this study. In an attempt to control for various confounds, we excluded children with multiple disabilities, children who did not use English as a primary language, and children with profound deafness, unilateral hearing loss, and children with cochlear implants. These exclusionary criteria limit our ability to generalize our results beyond this current subset of children who are hard of hearing. Future research may address the amount of daily hearing aid use in a wider population of children. An additional limitation is that we did not include the measures of the quality of the hearing aid fitting in our regression analyses. Although data were collected on quality of hearing aid fitting, this dimension of the work was judged to be beyond the scope of the current study and was reported elsewhere (McCreery, et al., in revision). Future research will explore the influence of quality of fitting on consistency of use.

The primary goal of the OCHL project is to investigate outcomes of children who are hard of hearing. It is not an intervention study; therefore, another limitation is that we did not control for variables such as the quality of the hearing aid fitting, counseling of parents with regards to hearing aid use or device troubleshooting, and quantity and quality of aural habilitation and intervention. The current findings serve as preliminary data on how much time young children are wearing amplification, a topic that has been neglected in the pediatric aural habilitation literature. These data indicate that while many parents consider their children to be full-time HA users, there are still a significant number of children who do not wear their devices on a consistent basis. Consistency of hearing aid use and its potential influence on children's outcomes deserves continued attention in future research.

There were six children who received cochlear implants following enrollment in the OCHL study. These children continue to be followed on an annual basis, consistent with participants who still use hearing aids, but data are not collected on the amount of time they wear their cochlear implant(s). Furthermore, cochlear implants do not have datalogging capacities like hearing aids. An important future direction would be to apply these same research questions to children with cochlear implants, and investigate differences in use time among children with unilateral, bilateral, and bimodal configurations. It would also be useful for audiologists to have access to datalogging information for cochlear implants as well as hearing aids. 


\section{Summary}

Our findings provide evidence that several child- and family-specific variables, including severity of hearing loss, chronological age, and maternal education level, were significantly related to the amount of time children wore their hearing aids based on parents' estimations of daily use time. Parental ratings regarding consistency of hearing aid use across different listening environments supported the regression analysis, as younger children and children with milder hearing losses wore their hearing aids less consistently than older children and children with moderate-to-severe hearing loss in a variety of contexts. Parents also reported on challenges to maintaining consistent hearing aid use, with child state issues (e.g., temper tantrums, illness, fatigue) being the most commonly reported concern. Finally, our findings suggest that while most parents overestimated the amount of time their child wore his or her hearing aids, the positive correlation between parents' subjective estimates and objective measures using datalogging was high. The relative difference between parents' estimations appears to be consistent, but these estimates are mediated by the age of the child. Therefore, clinicians should rely on datalogging and consistency ratings to monitor device use whenever possible. When it is not possible to obtain datalogging measures, clinicians should be aware that parents will usually overestimate average use time, particularly in the case of younger children.

\section{Acknowledgments}

This work was supported by National Institutes of Health Grants NIH/NIDCD 5 ROI DC009560-03 (co-principal investigators, J. Bruce Tomblin, University of Iowa and Mary Pat Moeller, Boys Town National Research Hospital). The following people provided support or assistance at various points in the project: J. Bruce Tomblin provided support and input throughout the project and Rick Arenas managed the subject database. A special thanks goes to Marlea O'Brien for coordinating the OCHL project, as well as to the examiners at the University of Iowa, Boys Town National Research Hospital and University of North Carolina-Chapel Hill and the families and children who participated in the research. The content of this project is solely the responsibility of the authors and does not necessarily represent the official views of the National Institute on Deafness and Other Communication Disorders or the National Institutes of Health.

\section{Works Cited}

Akaike H. A new look at the statistical model identification. IEEE Transactions on automatic model control. 1974; 19(6):716-723.

ANSI. S3.5-1997. Methods for Calculation of the Speech Intelligibility Index. New York: American National Standards Institute; 1997.

ANSI. S3.22-2003. Specifications of Hearing Aid Characteristics. New York: American National Standards Institute; 2003.

Bagatto M, Moodie S, Scollie S, Seewald R, Pumford J, Liu KP. Clinical protocols for hearing instrument fitting in the Desired Sensation Level method. Trends in Amplification. 2005; 9(4):199_ 226. [PubMed: 16424946]

Cappelli M, Daniels T, Durieux-Smith A, McGrath PJ, Neuss D. Social development of children with hearing impairments who are integrated into general education classrooms. The Volta Review. 1995; 97:197-208.

Carney AE, Moeller MP. Treatment efficacy: Hearing loss in children. Journal of Speech, Language, and Hearing Research. 1998; 41(1):S61-S84.

Daud MKM, Noor RM, Rahman NA, Sidek DS, Mohamed A. The effect of mild hearing loss on academic performance in primary school children. International Journal of Pediatric Otorhinolaryngology. 2010; 74(1):67-70. [PubMed: 19913305]

Davis JM, Elfenbein J, Schum R, Bentler RA. Effects of mild and moderate hearing impairments on language, educational, and psychosocial behavior of children. Journal of Speech and Hearing Disorders. 1986; 51(1):53-62. [PubMed: 3945060]

Elfenbein J. Monitoring preschoolers' hearing aids: Issues in program design and implementation. American Journal of Audiology. 1994; 3:65-70. 
Hicks CB, Tharpe AM. Listening effort and fatigue in school-age children with and without hearing loss. Journal of Speech, Language, and Hearing Research. 2002; 45:573-584.

Holte L, Walker E, Oleson J, Spratford M, Moeller MP, Roush P, et al. Factors Influencing Follow-up to Newborn Hearing Screening for Infants who are Hard-of-Hearing. American Journal of Audiology. in press.

Humes LE, Halling D, Coughlin M. Reliability and stability of various hearing-aid outcome measures in a group of elderly hearing-aid wearers. Journal of Speech and Hearing Research. 1996; 39(5): 923-935. [PubMed: 8898247]

McCreery RW, Bentler RA, Roush PA. The characteristics of hearing aid fittings in infants and young children. Ear and Hearing. in revision.

McFadden B, Pittman A. Effect of minimal hearing loss on children's ability to multitask in quiet and in noise. Language Speech and Hearing Services in Schools. 2008; 39:342-351.

Mehra S, Eavey RD, Keamy DG Jr. The epidemiology of hearing impairment in the United States: newborns, children, and adolescents. Otolaryngology--head and neck surgery: official journal of American Academy of Otolaryngology-Head and Neck Surgery. 2009; 140(4):461-472. [PubMed: 19328331]

Moeller MP. Optimizing early word learning in children with hearing loss: Summary of 2010 Marian Downs lecture. Audiology Today. 2010; 22:19-27.

Moeller MP, Hoover B, Peterson B, Stelmachowicz P. Consistency of hearing aid use in infants with early-identified hearing loss. American Journal of Audiology. 2009; 18(1):14-23. [PubMed: 19029531]

Moeller MP, Tomblin JB, Yoshinaga-Itano C, Connor CM, Jerger S. Current state of knowledge: language and literacy of children with hearing impairment. Ear and Hearing. 2007; 28(6):740-753. [PubMed: 17982362]

Mueller HG. Data logging: It's popular, but how can this feature be used to help patients? The Hearing Journal. 2007; 60(10):19-26.

Russ SA, White K, Dougherty D, Forsman I. Preface: newborn hearing screening in the United States: historical perspective and future directions. Pediatrics. 2010; 126(Suppl 1):S3-6. [PubMed: 20679318]

Sininger YS, Grimes A, Christensen E. Auditory development in early amplified children: factors influencing auditory-based communication outcomes in children with hearing loss. Ear and Hearing. 2010; 31(2):166-185. [PubMed: 20081537]

Spivak L, Sokol H, Auerbach C, Gershkovich S. Newborn hearing screening follow-up: factors affecting hearing aid fitting by 6 months of age. American Journal of Audiology. 2009; 18(1):2433. [PubMed: 19029532]

Taubman LB, Palmer CV, Durrant JD, Pratt S. Accuracy of hearing aid use time as reported by experienced hearing aid wearers. Ear and Hearing. 1999; 20(4):299-305. [PubMed: 10466566]

Yoshinaga-Itano C, Sedey AL, Coulter DK, Mehl AL. Language of early- and later-identified children with hearing loss. Pediatrics. 1998; 102(5):1161-1171. [PubMed: 9794949]

\section{Appendix A}

\begin{tabular}{|l|l|l|}
\hline DOMAINS ASSESSED: & MEASUREMENT INSTRUMENTS: & $\begin{array}{l}\text { AGE AT } \\
\text { TEST } \\
\text { (months) }\end{array}$ \\
\hline Presymbolic Communication & $\begin{array}{l}\text { Communication and Symbolic Behavior Scales: } \\
\text { Temptations }\end{array}$ & 18 \\
\hline & $\begin{array}{l}\text { Communication and Symbolic Behavior Scales } \\
\text { Caregiver Questionnaire }\end{array}$ & 18 \\
\hline Vocal Development Landmarks & Vocal Development Landmarks (created for study) & $6,12,18$ \\
\hline LANGUAGE MEASURES & & \\
\hline & Spontaneous Language Sample & $36,72,96$ \\
\hline
\end{tabular}

Lang Speech Hear Serv Sch. Author manuscript; available in PMC 2013 January 12. 


\begin{tabular}{|c|c|c|}
\hline DOMAINS ASSESSED: & MEASUREMENT INSTRUMENTS: & $\begin{array}{l}\text { AGE AT } \\
\text { TEST } \\
\text { (months) }\end{array}$ \\
\hline \multirow[t]{5}{*}{ Vocabulary (receptive \& expressive) } & $\begin{array}{l}\text { MacArthur Bates Communicative Development } \\
\text { Inventory (MBCDI) Words \& Gestures ( } 8 \text { to } 18 \\
\text { mos) }\end{array}$ & 12,18 \\
\hline & MBCDI Words \& Sentences (19 to $30 \mathrm{mos}$ ) & 24 \\
\hline & MBCDI Upper Extension (31 mos and up) & 36 \\
\hline & Peabody Picture Vocabulary Test-4 & $60,84,108$ \\
\hline & $\begin{array}{l}\text { Weschler Abbreviated Scale of Intelligence (WASI) } \\
\text { vocabulary }\end{array}$ & $72,84,96,108$ \\
\hline Verbal Reasoning & Preschool Language Assessment Instrument-2 & 60 \\
\hline \multirow[t]{4}{*}{ Global Rec-Exp Measure } & Mullen Scales of Early Learning & 12,24 \\
\hline & $\begin{array}{l}\text { Comprehensive Assessment of Spoken Language } \\
\text { 3-4 Core }\end{array}$ & 36,48 \\
\hline & $\begin{array}{l}\text { Comprehensive Assessment of Spoken Language } \\
5-6 \text { Core }\end{array}$ & 72 \\
\hline & $\begin{array}{l}\text { Comprehensive Assess. of Spoken Language 7-10 } \\
\text { Core }\end{array}$ & 96 \\
\hline Narrative & Candy Stealing Story & 84,108 \\
\hline \multirow[t]{2}{*}{ Elicitation of mental state stories } & Explanation of Action Movies & 84,108 \\
\hline & $\begin{array}{l}\text { Theory of Mind measures (Standard False Belief } \\
\text { Tasks) }\end{array}$ & 60,72 \\
\hline \multirow[t]{2}{*}{ Morphology } & $\begin{array}{l}\text { Clinical Evaluation of Language Fundamentals-4 } \\
\text { Word Structure }\end{array}$ & 60,84 \\
\hline & $\begin{array}{l}\text { Morphological Elicitation Procedure (created for } \\
\text { study) }\end{array}$ & 36,48 \\
\hline \multicolumn{3}{|l|}{ SPEECH PRODUCTION MEASURES } \\
\hline \multirow[t]{3}{*}{ Speech Production } & Goldman-Fristoe Test of Articulation & $36,60,84,108$ \\
\hline & Open \& Closed Set Test (D. Ertmer) & 24 \\
\hline & $\begin{array}{l}\text { Conditioned Assessment of Speech Perception and } \\
\text { Production P (Ertmer \& Stoel-Gammon, 2003) }\end{array}$ & 24 \\
\hline Speech Intelligibility & Beginner's Intelligibility Test & 60,84 \\
\hline \multicolumn{3}{|l|}{ ACADEMIC MEASURES } \\
\hline Phonological Processing \& Memory & $\begin{array}{l}\text { Comprehensive Test of Phonological Processing } \\
\text { (CTOPP) }\end{array}$ & $60,84,108$ \\
\hline $\begin{array}{l}\text { Phonological Awareness \& Print } \\
\text { Knowledge }\end{array}$ & Test of Preschool Early Literacy (TOPEL) & 48 \\
\hline Print Knowledge & TOPEL & 60 \\
\hline Word Attack & $\begin{array}{l}\text { Woodcock Reading Mastery Test-R (WRMT-R) } \\
\text { Word Attack }\end{array}$ & 72,96 \\
\hline Word Recognition & WRMT-R Word Identification & 72,96 \\
\hline Reading Comprehension & WRMT-R Reading Comprehension & 72,96 \\
\hline Spelling & $\begin{array}{l}\text { Weschler Individual Achievement Test (WIAT)-II- } \\
\text { A }\end{array}$ & 84,108 \\
\hline Math Reasoning & WIAT-II-A & 84,108 \\
\hline $\begin{array}{l}\text { HEARING FUNCTION, AUDIBIITY \& } \\
\text { SPEECH PERCEPTION }\end{array}$ & & \\
\hline
\end{tabular}




\begin{tabular}{|c|c|c|}
\hline DOMAINS ASSESSED: & MEASUREMENT INSTRUMENTS: & $\begin{array}{l}\text { AGE AT } \\
\text { TEST } \\
\text { (months) }\end{array}$ \\
\hline \multirow[t]{4}{*}{ Audiologic Evaluation } & History, Audiogram (VRA) + Tymps & Every visit \\
\hline & History, Audiogram $(\mathrm{CPA})+$ Tymps & Every visit \\
\hline & History, Audiogram (Conventional) + Tymps & Every visit \\
\hline & Electroacoustic Analysis 60/90 Curves & Every visit \\
\hline Hearing Aid Function & Aided Speech Intelligibility Index (Verifit SII) & Every visit \\
\hline Audibility & Hearing Aid Checklist & Every visit \\
\hline Hearing Aid Use & Little Ears Questionnaire & $12,18,24$ \\
\hline \multirow[t]{7}{*}{ Speech Perception } & $\begin{array}{l}\text { Parent's Evaluation of Aural/Oral Performance of } \\
\text { Children (PEACH) }\end{array}$ & $\begin{array}{l}18,24 \\
\text { (depending on } \\
\text { Little Ears } \\
\text { score) }\end{array}$ \\
\hline & Early Speech Perception (ESP) lo-verbal & 24 \\
\hline & ESP & 24,36 \\
\hline & Phonetically Balanced Kindergarten (PBK) & 60,72 \\
\hline & $\begin{array}{l}\text { Computer-Assisted Speech Perception Assessment } \\
\text { (CASPA) }\end{array}$ & $84,96,108$ \\
\hline & $\begin{array}{l}\text { Multisyllable Lexical Neighborhood Test (MLNT) } \\
\& \text { Lexical Neighborhood Test (LNT) }\end{array}$ & 48 \\
\hline & Speech Spatial Qualities (SSQ) - revised & $48,72,96$ \\
\hline \multicolumn{3}{|c|}{$\begin{array}{l}\text { PSYCHOSOCIAL, BEHAVIORAL \& } \\
\text { FAMILY MEASURES }\end{array}$} \\
\hline \multirow[t]{5}{*}{ Cognitive Skills } & $\begin{array}{l}\text { Weschler Preschool \& Primary Scale of Intelligence } \\
\text { (WPPSI) }\end{array}$ & 48 \\
\hline & Weschler Abbreviated Scale of Intelligence (WASI) & 72,96 \\
\hline & Head to Toes Task & 72 \\
\hline & Vineland Adaptive Behavior Scales & $12,24,36,48$ \\
\hline & Friendship Interview & 72,96 \\
\hline Social Skills & Child Behavior Checklists (CBCL) & $24,48,72,96$ \\
\hline \multirow[t]{2}{*}{ Behavior } & Teacher Report Forms (TRF) & $48,72,96,108$ \\
\hline & Adult Perceptions II & 60 \\
\hline Parenting and Discipline & $\begin{array}{l}\text { Family Activities Checklist \& Parent Issues } \\
\text { Checklist }\end{array}$ & $48,72,96$ \\
\hline Family Activities & Infant Behavior Questionnaire & 12 \\
\hline \multirow[t]{3}{*}{ Child Temperament } & Early Childhood Behavior Questionnaire & 36 \\
\hline & Children's Behavior Questionnaire - short version & 48,72 \\
\hline & Social Competence \& Behavior Evaluation Scale & $60,84,108$ \\
\hline \multirow[t]{4}{*}{ School Behaviors (teacher report) } & Teacher Predictions of Peer Nominations & 84,108 \\
\hline & Direct and Indirect Aggression Scale - Teacher & 84,108 \\
\hline & Direct and Indirect Aggression Scale - Parent & 84,108 \\
\hline & $\begin{array}{l}\text { Screening Identification For Targeting Educational } \\
\text { Risk (SIFTER - preschool \& school age) }\end{array}$ & $\begin{array}{l}36,48,60,72 \\
84,96\end{array}$ \\
\hline $\begin{array}{l}\text { FAMILY BACKGROUND \& } \\
\text { INTERVENTION MEASURES }\end{array}$ & & \\
\hline
\end{tabular}




\begin{tabular}{|l|l|l|}
\hline DOMAINS ASSESSED: & MEASUREMENT INSTRUMENTS: & $\begin{array}{l}\text { AGE AT } \\
\text { TEST } \\
\text { (months) }\end{array}$ \\
\hline Intervention Program Measures & OCHL Service Provider Survey (SPS)- Audiology & Every visit \\
\hline & OCHL SPS 0 to 3 years & $\begin{array}{l}\text { Each visit 6- } \\
35 \mathrm{~m}\end{array}$ \\
\hline & OCHL SPS Preschool & $\begin{array}{l}\text { Each visit 35- } \\
59 \mathrm{~m}\end{array}$ \\
\hline & OCHL SPS School-Age & $\begin{array}{l}\text { Each visit } 60 \mathrm{~m} \\
+\end{array}$ \\
\hline Family Background \& Satisfaction & OCHL Family Interview & $\begin{array}{l}6 \mathrm{months} \text { after } \\
\text { every visit }\end{array}$ \\
\hline Family Quality of Life & Beach Center Family Survey & $24,48,72,96$ \\
\hline
\end{tabular}

\section{Appendix B}

\section{Checklist for Hearing Aid and FM Fitting}

Subject \#: D.O.B. Date Completed:

1. Hearing Aid Make: 2. Model: 3. Type:

4. Fitting: monaural binaural

5. FM use: home school

6. During the first year after your child was fit with hearing aids, how many hours a day did she/he wear them?___ Hours___ Child was fit less than 1 year ago

7. Current use time:

8. How many hours a day does your child currently wear the aid(s)?

Monday-Friday

Saturday-Sunday

Data Logging: Right

Left

9. When your child wakes from sleep (morning or nap), how much time does she/he require before the hearing aid goes on?

Put an $\mathrm{X}$ in the boxes below to indicate how consistently your child uses HAs in the situations listed:

\begin{tabular}{|l|l|l|l|l|l|l|}
\hline Situation & $\begin{array}{l}\text { Never } \\
(\mathbf{0})\end{array}$ & $\begin{array}{l}\text { Rare } \\
(\mathbf{1})\end{array}$ & Sometimes (2) & $\begin{array}{l}\text { Often } \\
\mathbf{( 3 )}\end{array}$ & $\begin{array}{l}\text { Always } \\
\mathbf{( 4 )}\end{array}$ & N/A \\
\hline 10. Car & & & & & & \\
\hline 11.PreSchool/School & & & & & & \\
\hline 12.Day Care & & & & & & \\
\hline 13.Meal Time & & & & & & \\
\hline 14.Playing Alone & & & & & & \\
\hline 15.Book Sharing & & & & & & \\
\hline 16.Playground & & & & & & \\
\hline $\begin{array}{l}\text { 17.Public (store, zoo, } \\
\text { restaurant) }\end{array}$ & & & & & & \\
\hline
\end{tabular}

18. Are there any particularly challenging times or situations for you or the child for keeping the hearing aid(s) on? 


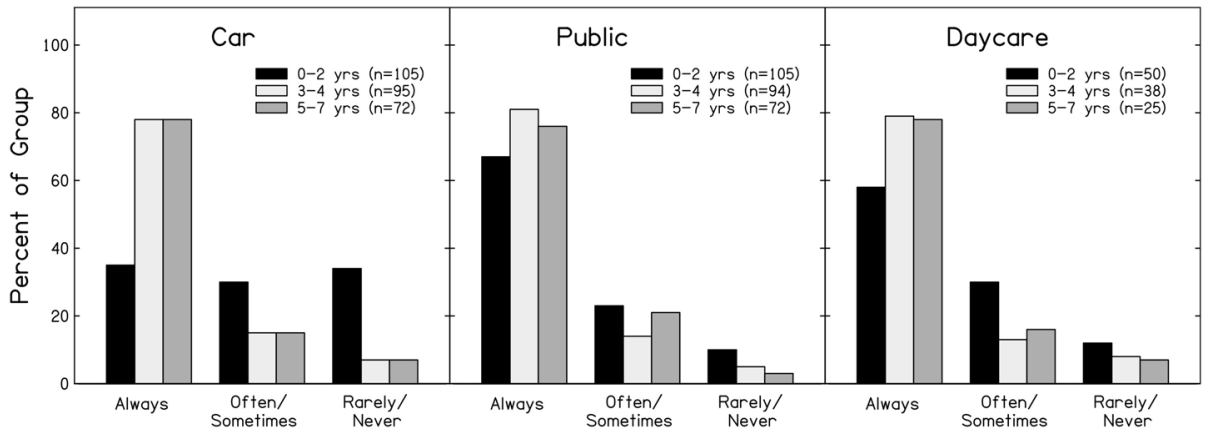

Figure 1.

Ratings for consistency of hearing aid use in the car, in public, and at daycare in relation to age. 


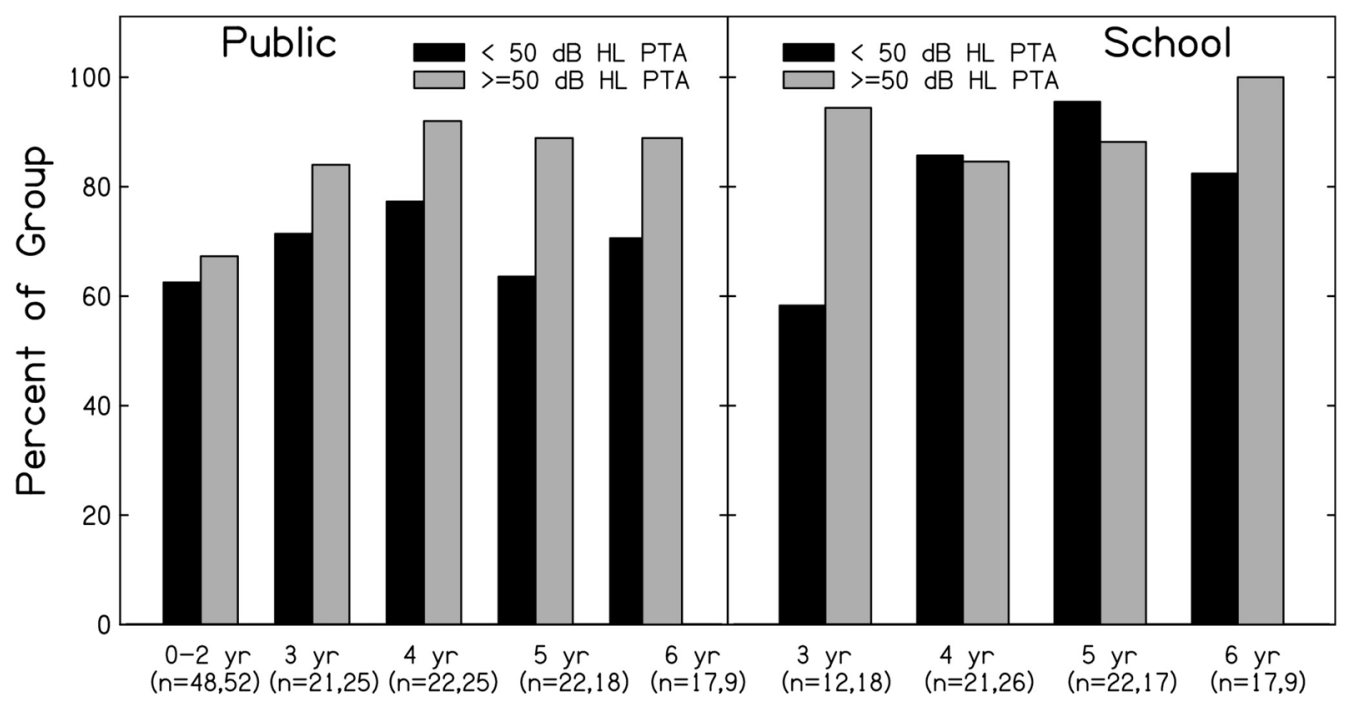

Figure 2.

Consistent hearing aid use in public and at school in relation to better-ear PTA. 


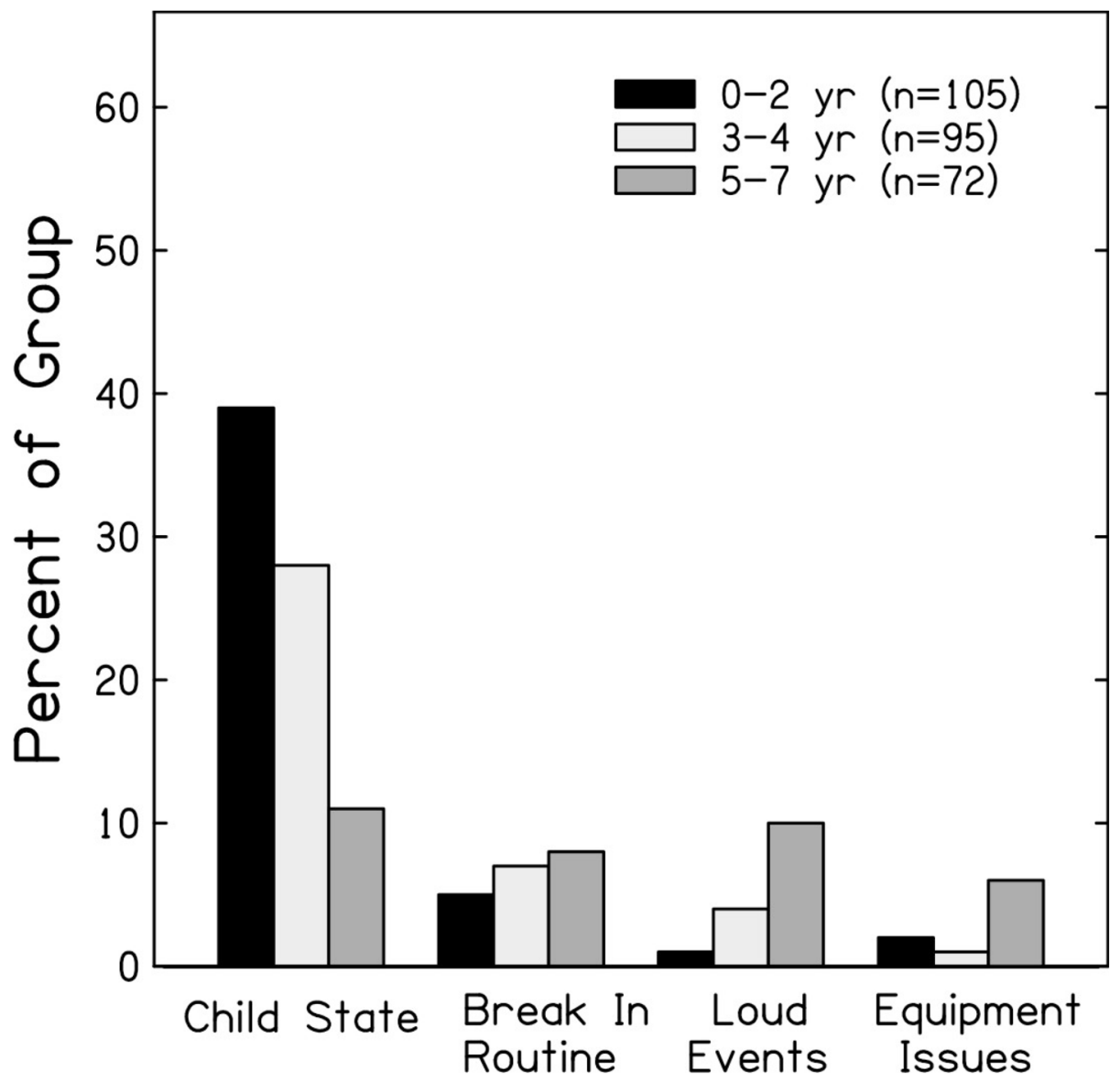

Figure 3.

Reports about challenges to consistent hearing aid use in relation to age. 


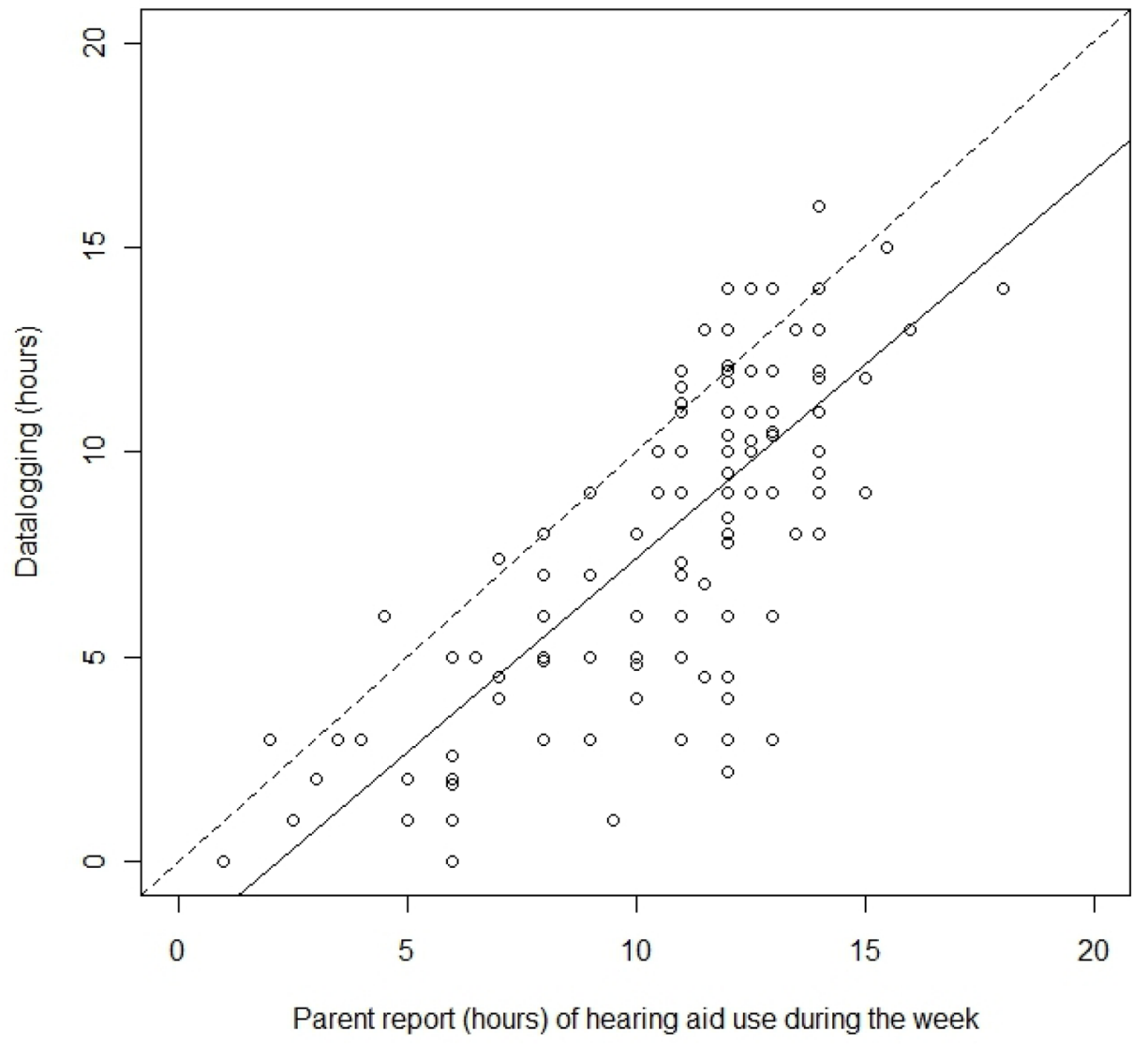

Figure 4.

Hearing aid use time by parent report and datalogging. The solid line represents the regression line and dotted lines represent $95 \%$ confidence intervals. 


\section{Table 1}

Arbitrary levels for maternal education $(\mathrm{N}=259)$.

\begin{tabular}{ll}
\hline Maternal education level & $\boldsymbol{N}$ \\
\hline High School or less & 39 \\
Vocational School/some college & 88 \\
College & 68 \\
Graduate School & 64 \\
\hline
\end{tabular}

Note. Thirteen mothers did not report education level. 


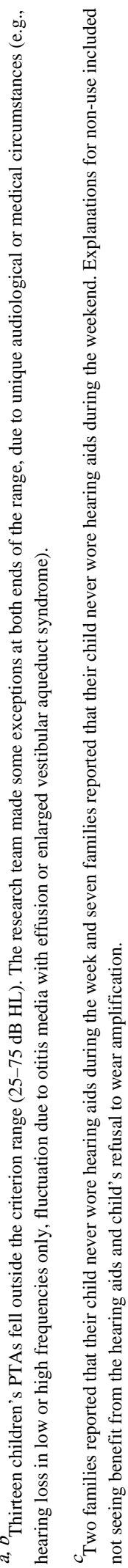

$\frac{\substack{0 \\ \frac{0}{0}}}{\stackrel{0}{\circ}}$

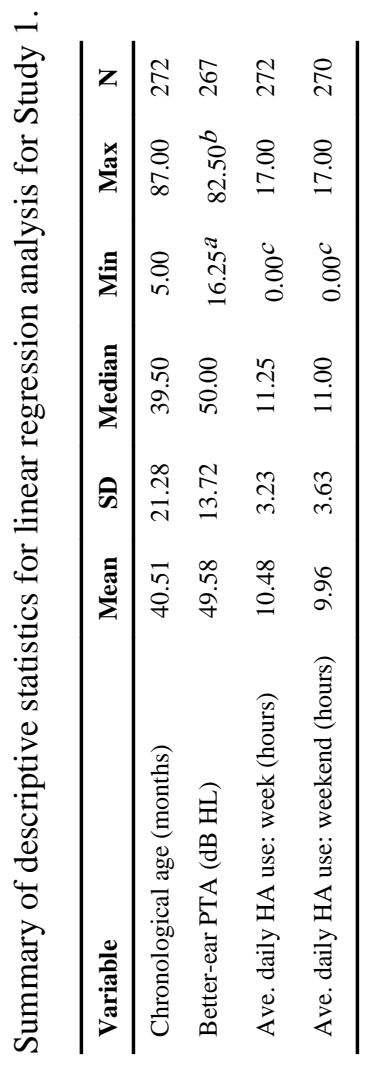

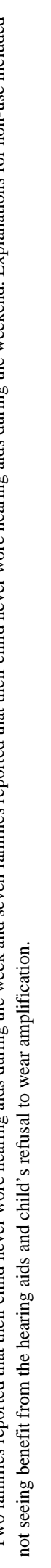

Lang Speech Hear Serv Sch. Author manuscript; available in PMC 2013 January 12. 


\section{Table 3}

Summary of parameter estimates for linear regression analysis for variables predicting caregiver report of daily hearing aid use.

\begin{tabular}{lcccc}
\hline Parameter & Estimate $(\boldsymbol{\beta})$ & $\boldsymbol{S E}$ & $\boldsymbol{t}$ & $\boldsymbol{p}$-value \\
\hline Intercept & 3.42 & 0.98 & 3.49 & 0.001 \\
Site: Iowa & -1.07 & 0.40 & -2.64 & 0.009 \\
Site: Boys Town & -0.14 & 0.40 & -0.35 & 0.730 \\
Gender: Female & 0.26 & 0.34 & 0.77 & 0.443 \\
Maternal education: High School or less & -0.90 & 0.55 & -1.64 & 0.103 \\
Maternal education: Vocational/some college & 0.20 & 0.44 & 0.45 & 0.651 \\
Maternal education: College & 0.94 & 0.46 & 2.02 & 0.044 \\
Better-ear PTA & 0.05 & 0.01 & 3.84 & 0.0002 \\
Chronological Age & 0.20 & 0.03 & 6.09 & $<0.001$ \\
Chronological Age Squared & -0.002 & 0.0004 & -4.04 & $<0.001$ \\
\hline
\end{tabular}

Note: North Carolina, Male, and Maternal education: Graduate school are not listed in the table. Those levels were used as the baseline reference level in the regression analysis. 


\section{Table 4}

Daily hearing aid use time in hours (based on caregiver report) during weekdays by maternal education level, testing site, better-ear PTA, and chronological age.

\begin{tabular}{lcc}
\hline Maternal education level (N = 259) & $\boldsymbol{M}$ & $\boldsymbol{S} \boldsymbol{E}$ \\
High School or less & 8.92 & 0.62 \\
Vocational school/some college & 10.66 & 0.32 \\
College & 11.28 & 0.29 \\
Graduate School & 10.68 & 0.42 \\
Testing site (N = 272) & $\boldsymbol{M}$ & $S E$ \\
Iowa & 9.83 & 0.39 \\
Boys Town & 10.35 & 0.32 \\
UNC & 11.14 & 0.31 \\
Better-ear PTA (N =272) & $M$ & $S E$ \\
< 50 dB HL & 9.95 & 0.28 \\
$>$ 50 dB HL & 11.12 & 0.26 \\
Chronological age $(\mathrm{N}=251)$ & $M$ & $S E$ \\
Infants $(0-2 ; 11)$ & 8.24 & 0.37 \\
Preschool (3-4;11) & 10.91 & 0.30 \\
School-age (5-6;11) & 11.68 & 0.32 \\
\hline
\end{tabular}


Table 5

Percentage of responses indicating full-time hearing aid use in different contexts for infant age groups.

\begin{tabular}{lccc}
\hline Age & Car \% (n) & Public \% (n) & Daycare \% (n) \\
\hline 6 months & $31(16)$ & $63(16)$ & $50(8)$ \\
12 months & $14(28)$ & $50(28)$ & $40(10)$ \\
18 months & $23(26)$ & $65(26)$ & $58(12)$ \\
24 months & $63(35)$ & $83(35)$ & $70(20)$ \\
\hline
\end{tabular}




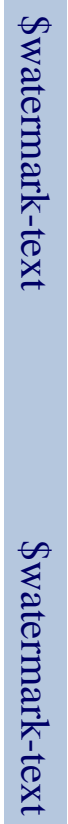

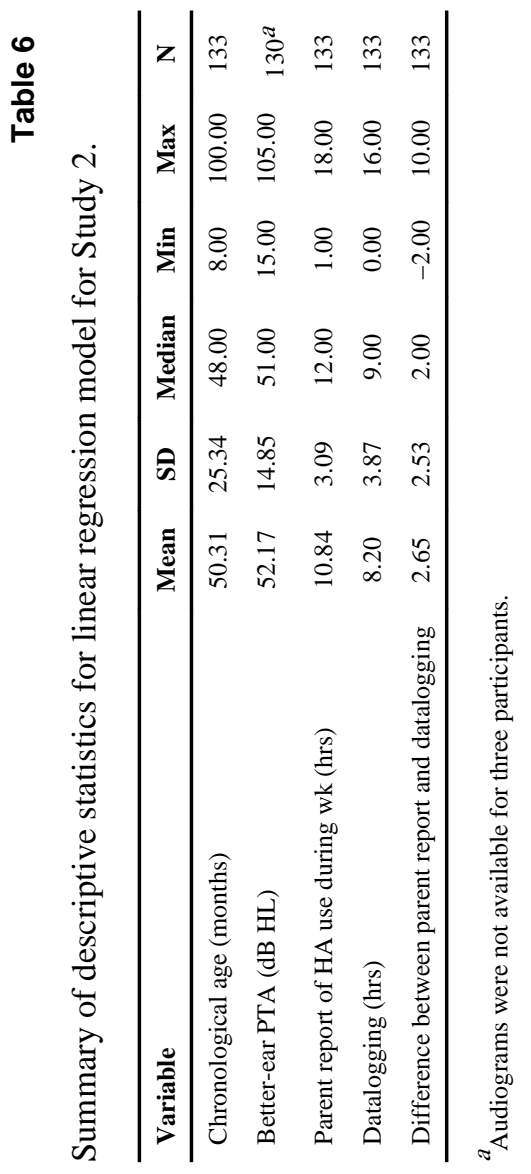




\section{Table 7}

Summary of parameter estimates for linear regression analysis for variables predicting the difference between datalogging and parent report of hearing aid use.

\begin{tabular}{lcccc}
\hline Parameter & Estimate $(\boldsymbol{\beta})$ & $\boldsymbol{S E}$ & $\boldsymbol{t}$ & $\boldsymbol{p}$-value \\
\hline Intercept & 3.52 & 1.08 & 3.24 & 0.002 \\
Center: Iowa & 0.37 & 0.47 & 0.77 & 0.44 \\
Center: Boys Town & -0.03 & 0.74 & 0.03 & 0.97 \\
Gender: Female & 0.28 & 0.48 & 0.58 & 0.56 \\
Mother's education: High School or less & 0.73 & 0.82 & 0.89 & 0.38 \\
Mother's education: Vocational school/some college & 1.58 & 0.61 & 2.57 & 0.01 \\
Mother's education: College & 0.63 & 0.56 & 1.12 & 0.26 \\
Better-ear PTA & -0.01 & 0.0149 & 0.80 & 0.43 \\
Chronological Age & -0.03 & 0.01 & 3.47 & 0.001 \\
\hline
\end{tabular}

